\title{
The impact of extreme climate change on the fluctuation of electricity energy demand- Evidence from China's prefecture-level cities
}

\author{
Yudong Tan ${ }^{1,2}$, Tong Jiang ${ }^{1,2}$, Hao Xiao ${ }^{3}$, Jingyi Tang ${ }^{3, *}$, and Zhen $\mathrm{Jia}^{3}$ \\ ${ }^{1}$ Energy Internet Supply and Demand Operation Hunan Key Laboratory, 410000 Changsha, China \\ ${ }^{2}$ Economic and Technical Research Institute of State Grid Hunan Power Company, 410000 Changsha, \\ China \\ ${ }^{3}$ Hunan University, School of economics and trade, 410079 Changsha, China
}

\begin{abstract}
Climate change directly make the demand for electricity diversified and uncertain, which increase the risk of power grid operation. This paper attempts to explore the impact of extreme climate change on the fluctuation of China's electricity energy demand from the perspective of climate change. Based on the panel data of 90 prefecture-level cities in China from 1989 to 2017, the author builds an econometric model to test the impact of extreme low temperature and extreme high temperature on electricity demand. The results show that the occurrence of extreme high temperature weather has a positive effect on residential electricity demand while the emergence of extreme low temperature weather has a negative effect.
\end{abstract}

\section{Introduction}

Due to the diversity and uncertainty of power demand, the power generation capacity set to meet the maximum demand of customers is largely idle, which not only increases the cost and operation risk of power enterprises, but also increases the electricity burden of customers. So, It is of great significance to optimize power load planning (Zhang, 2018 ${ }^{[1]}$; $\mathrm{Su}$ et al, 2019 $\left.{ }^{[2]}\right)$. Historically, dozens of existing studies have shown that a country's electricity energy consumption is affected by its economic structure, energy structure and energy policies (Chung et al, 2009 ${ }^{[3]}$; Wu et al, 2017 ${ }^{[4]}$; Sun et al, 2021 $1^{[5]}$ ). At the same time, energy consumption is also affected by temperature, weather and even extreme weather (Kraft et al, 1978 ${ }^{[6]}$; Ihara et al, 2008 ${ }^{[7]}$; Tarek et al, 2016 ${ }^{[8]}$ ). Many studies isolate separate temperature effects by using fixed effects(Wenz, et al 2017 ${ }^{[9]}$;Wang, 2018 ${ }^{[10]}$; Anna et al, $\left.2019^{[11]}\right)$. However, existing studies on this are still insufficient.

Another deficiency of existing research is that there are relatively few systematic studies the world's largest electricity energy consumer-China. For example, the sample used by Yating Li et al (2019) ${ }^{[12]}$ is the daily data of a certain district of Shanghai, and it is found that there is a symmetrical U-shaped relationship between residential electricity consumption and daily temperature in Shanghai, China. Karimu A et al (2015) ${ }^{[13]}$ used the

* Corresponding author: 1330242354@qq.com 
SVAR model to study 11 sub-Saharan African countries.

Compared with previous studies, the contributions of this article include three aspects: Firstly, from the perspective of index construction, this paper constructs an extreme value model based on high-frequency data samples to describe the extreme temperature. Secondly, in terms of data selection, the data time span is more in line with the logic of climate change, and this sample set includes samples of cities of different sizes and development stages in all provinces of China. Thirdly, from the perspective of research content, different from the current study focusing on the impact of extreme high temperature on power demand, this study included both extreme high temperature and extreme low temperature into the model, so as to capture the impact of temperature more perfectly.

\section{Empirical framework and data sources}

\subsection{Econometric specification}

In order to study the impact of extreme weather on residential electricity consumption, the following estimation model was used:

$$
\ln E_{i t}=\alpha W_{i t}+\beta Z_{i t}+\varepsilon_{i t}
$$

Wherein, $E_{i t}$ represents the electricity consumption of city $i$ in year $t$. In order to adjust dimensional and stable data, we choose to take logarithm of the dependent variable Eit. Compared with the commercial and industrial sectors, the residential sector varies more with extreme weather. So, the electricity consumption in this study refers to the local residents' electricity consumption. Then, Wit represents the main explanatory variables including high temperature and low temperature, and we chose to get the nonlinear effects of extreme temperatures by $\mathrm{Tmax}_{\mathrm{it}}$ and $\mathrm{Tmin}_{\mathrm{it}}$, respectively. Finally, Zit represents for other control variables, including real GDP, the number of population and wage level. We estimated the following models and tested the robustness based on the hypothesis of the relationship between extreme weather and residential electricity consumption.

$$
\begin{gathered}
\ln E_{i t}=\alpha_{1} \operatorname{Tmax}_{i t}+\alpha_{2} \operatorname{Tmin}_{i t}+\beta Z_{i t}+\varepsilon_{i t} \\
\operatorname{Tmax}_{i t}=\sum_{j=1}^{365} \max _{j t}, \max _{i t}=\left\{\begin{array}{c}
1, \text { the temperature on the } \mathrm{j} \text { day is the highest in } 29 \text { years } \\
0 \text {, the temperature on the } \mathrm{j} \text { day is } n o t \text { the highest in } 29 \text { years }
\end{array}\right. \\
\operatorname{Tmin}_{i t}=\sum_{j=1}^{365} \min _{j t}, \min _{i t}=\left\{\begin{array}{c}
1, \text { the temperature on the } \mathrm{j} \text { day is the lowest in } 29 \text { years } \\
0, \text { the temperature on the } \mathrm{j} \text { day is not the lowest in } 29 \text { years }
\end{array}\right.
\end{gathered}
$$

Among them, $\operatorname{Tmax}_{\mathrm{it}}$ represents the number of extreme high temperature weather in $\mathrm{i}$ city in the year t. According to the statistics of the temperature in 29 years, the so-called extreme high temperature is the historical extreme value within the statistical range. If the extreme high temperature on January 1 in city $i$ occurs in year 2000 , then the $\max _{\mathrm{jt}}$ in year 2000 is 1 , and all other years are 0 . The sum of $\max _{\mathrm{jt}}$ in year $t$ of the city is $\operatorname{Tmax}_{\mathrm{it}}$. $\operatorname{Tm}_{\mathrm{min}}$ it represents the number of extreme low temperature weather in city $i$ in year $t$.

\subsection{Variable selection and data sources}

Limited to the availability of data, this paper selects 90 prefecture-level cities from 30 provinces in China (except Hong Kong, Macao, Taiwan and Tibet) as samples. "Extreme 
high, low temperature, and precipitation events" are defined as events with a small probability of temperature or precipitation exceeding historical extremes. Temperature plays a leading role in influencing power consumption. Therefore, this paper uses the frequency of extreme high (and low) temperature to measure extreme weather. Due to data limitations, this paper collects the daily temperature data in 1989-2017, which is from China Meteorological data network. The power consumption of residents in 90 prefecture-level cities from 1989 to 2017 was used as a variable to indicate the intensity of regional residents' electricity demand. Data came from China Urban Statistical Yearbook. In addition, this paper selects three variables which are closely related to residential electricity demand as control variables, namely the actual GDP, population, and wage level. Data for all control variables were obtained from China Urban Statistical Yearbook.

Table 1 is the statistical description of the variables of the whole sample. It is found that the maximum and minimum values of power consumption and air temperature of all cities show typical regional and annual imbalances. Taking temperature as an example, the frequency of maximum high temperature is 47 , and the minimum value is 0 .

Table 1. Statistical description of the full sample variables.

\begin{tabular}{cccccc}
\hline Variable & Observation & Mean & $\begin{array}{c}\text { Standard } \\
\text { deviation }\end{array}$ & Maximum & Minimum \\
\hline LnE & 2497 & 10.31 & 1.53 & 14.59 & 5.70 \\
Tmax & 2497 & 13.02 & 7.04 & 47 & 0 \\
Tmin & 2497 & 13.11 & 7.36 & 46 & 0 \\
GDP & 2497 & $1.33 \mathrm{e}+07$ & $2.70 \mathrm{e}+07$ & $2.82 \mathrm{e}+08$ & 27200 \\
Wage & 2497 & 1962265 & 6062071 & $1.02 \mathrm{e}+08$ & 7.07 \\
Pop & 2497 & 1155.25 & 679.65 & 2331 & 1 \\
\hline
\end{tabular}

\section{Empirical Results}

Table 2. Regression results of residents' electricity demand affected by extreme weather.

\begin{tabular}{cccccc}
\hline & Model 1 & Model 2 & Model 3 & Model 4 & Model 5 \\
\hline \multirow{2}{*}{ Tmax } & $0.023^{* * *}$ & $0.040^{* * *}$ & $0.029^{* * *}$ & $0.028^{* * *}$ & $0.026^{* * *}$ \\
& $(7.00)$ & $(14.01)$ & $(11.63)$ & $(11.37)$ & $(10.81)$ \\
Tmin & $-0.017^{* * *}$ & $-0.034^{* * *}$ & $-0.024^{* * *}$ & $-0.023^{* * *}$ & $-0.022^{* * *}$ \\
& $(-5.09)$ & $(-12.78)$ & $(-9.96)$ & $(-9.63)$ & $(-9.04)$ \\
GDP & $3.36 \mathrm{e}-08^{* * *}$ & & $2.33 \mathrm{e}-08^{* * *}$ & $2.29 \mathrm{e}-08^{* * *}$ & $2.10 \mathrm{e}-08^{* * *}$ \\
& $(40.68)$ & & $(29.09)$ & $(28.31)$ & $(27.15)$ \\
pop & $0.0003^{* * *}$ & & & $0.0002^{* * *}$ & $0.0002^{* * *}$ \\
& $(8.96)$ & & & $(4.39)$ & $(3.54)$ \\
wage & $1.92 \mathrm{e}-08^{* * *}$ & & & & $5.14 \mathrm{e}-08^{* * *}$ \\
& $(5.17)$ & & & & $(15.15)$ \\
Constant & $9.443^{* * *}$ & $10.263^{* * *}$ & $9.947^{* * *}$ & $9.732^{* * *}$ & $9.753^{* * *}$ \\
& $(116.53)$ & $(173.94)$ & $(190.84)$ & $(127.49)$ & $(132.47)$ \\
Year fix effects & & Yes & Yes & Yes & Yes \\
City fix effects & & Yes & Yes & Yes & Yes \\
Adjusted R ${ }^{2}$ & 0.4804 & 0.451 & 0.551 & 0.351 & 0.425 \\
$\mathrm{~N}$ & 2241 & 2497 & 2396 & 2326 & 2241 \\
\hline
\end{tabular}

Note: The values in brackets are $\mathrm{T}$ values, and ${ }^{*}, * * * * *$ mean significant at the confidence levels of $10 \%, 5 \%$ and $1 \%$, respectively. Cluster at the city level. The following table has the same comments. Taking formula (2) as basic model, we estimated the impact of extreme climate change on residents' electricity consumption. Table 2 shows the benchmark results of regression analysis. The estimation coefficients of Tmax and Tmin pass the test at the significance level of $1 \%$. Specifically, all the estimated coefficients of Tmax are positive, indicating that the frequency of extreme high temperature weather generally has a positive effect on 
residential electricity demand; All the estimated coefficients of Tmin are negative, which indicates that the frequency of extremely low temperature weather has a negative impact on residential electricity demand. Taking the Model 5 in Table 2 as an example, the estimated coefficient of Tmax is 0.026 , showing that the residential electricity demand measured by residential electricity consumption will increase by $2.6 \%$ for every 1 increase in the occurrence of extreme high temperature weather. When the coefficient of Tmin is -0.022 , the occurrence of extreme low temperature weather increases by 1 , the residential electricity demand measured by residential electricity consumption will decrease by $2.2 \%$. However, the positive effect of extreme high temperature weather is stronger than the negative effect of extreme low temperature weather, and the total effect is positive. The more extreme weather occurs, the greater the electricity demand of residents.

Extreme climate change in China has only appeared in recent years, especially after 2000. With China's integration into the WTO, the process of globalization is further promoted, and more and more greenhouse gases are discharged into the atmosphere (Vennemo et al, 2008 ${ }^{[14]}$; Gary, 2009 ${ }^{[15]}$ ). Based on this, this paper takes 2000 as the dividing line of sample time, and estimates the sample groups around 2000 respectively.

Table 3. Regression results of extreme weather affecting residential electricity demand before 2000 .

\begin{tabular}{ccccc}
\hline & Model 1 & Model 2 & Model 3 & Model 4 \\
\hline Tmax & $0.039^{* * *}$ & $0.025^{* * *}$ & $0.022^{* * *}$ & $0.020^{* * *}$ \\
& $(10.18)$ & $(7.18)$ & $(6.23)$ & $(5.32)$ \\
Tmin & $-0.021^{* * *}$ & $-0.012^{* * *}$ & $-0.009^{* * *}$ & $-0.009^{*}$ \\
& $(-6.61)$ & $(-3.91)$ & $(-2.99)$ & $(-2.51)$ \\
GDP & & $1.48 \mathrm{e}-07^{* * *}$ & $1.34 \mathrm{e}-07^{* * *}$ & $1.91 \mathrm{e}-07^{* * *}$ \\
& & $(18.54)$ & $(16.28)$ & $(9.98)$ \\
pop & & $0.001^{* * *}$ & $0.001^{* * *}$ \\
& & & $(6.84)$ & $(6.74)$ \\
wage & & & $-4.57 \mathrm{e}-07^{* * *}$ \\
& & & & $(-3.39)$ \\
Constant & $9.301^{* * *}$ & $8.928^{* * *}$ & $8.533^{* * *}$ & $8.569^{* * *}$ \\
Year fix effects & $(125.5)$ & $(129.27)$ & $(91.7)$ & $(85.65)$ \\
City fix effects & Yes & Yes & Yes & Yes \\
Adjusted R $\mathrm{R}^{2}$ & 0.471 & Yes & Yes & Yes \\
$\mathrm{N}$ & 1021 & 0.452 & 0.561 & 0.355 \\
\hline
\end{tabular}

Table 4. Regression results of extreme weather affecting residential electricity demand after 2000.

\begin{tabular}{ccccc}
\hline & Model 1 & Model 2 & Model 3 & Model 4 \\
\hline Tmax & -0.0002 & -0.0004 & -0.002 & -0.0009 \\
& $(-0.08)$ & $(-0.19)$ & $(-1.23)$ & $(-0.54)$ \\
Tmin & $-0.0095^{* * *}$ & $-0.006^{* * *}$ & $-0.0049^{*}$ & $-0.005^{* * *}$ \\
& $(-4.16)$ & $(-2.95)$ & $(-2.54)$ & $(-2.75)$ \\
GDP & & $1.36 \mathrm{e}-08^{* * *}$ & $8.53 \mathrm{e}-09^{* * *}$ & $7.99 \mathrm{e}-09^{* * *}$ \\
& & $(21.1)$ & $(11.32)$ & $(11.18)$ \\
pop & & $0.0047^{* * *}$ & $0.004^{* * *}$ \\
& & & $(11.72)$ & $(10.33)$ \\
wage & & & & $3.14 \mathrm{e}-08^{* * *}$ \\
& & & & $(12.60)$ \\
Constant & $11.09^{* * *}$ & $10.741^{* * *}$ & $8.337^{* * *}$ & $8.634^{* * *}$ \\
Year fix effects & $(247.74)$ & $(260.27)$ & $(39.89)$ & $(43.33)$ \\
City fix effects & Yes & Yes & Yes & Yes \\
Adjusted R ${ }^{2}$ & 0.571 & Yes & Yes & Yes \\
$\mathrm{N}$ & 1476 & 0.552 & 0.551 & 0.423 \\
\hline
\end{tabular}

As can be seen from the results in Table 3 that all the estimation coefficients of 
variables Tmax and Tmin have passed the hypothesis test, which shows that the above estimation results are robust. It is the same as the total sample estimate, the positive effect of extreme hot weather is stronger than the negative effect of extreme cold weather. Before 2000, the appearance of extreme low temperature weather was more concentrated in May, June and July. The appearance of extreme low temperature just alleviated the hot weather, and the electricity demand of residents for heating would be reduced correspondingly. The extremely cold weather in winter was relatively rare.

It can be seen from Table 4 that the estimated coefficients of Tmax do not pass the hypothesis test, the coefficients of Tmin pass the hypothesis test. The reason is that the global temperature has generally increased since 2000, while the extreme high temperature weather is not obvious. To analyze the impact of extreme temperature on residential electricity consumption, we take Model 4 in Table 4 as an example, and find that the coefficient of Tmin is -0.005 . This means that for every increase in the number of extreme low temperature weather occurrences, residential electricity demand will decrease by $0.5 \%$.

\section{Conclusion}

Based on the panel data of 90 prefecture-level cities in China in 1989-2017, this paper conducts an empirical analysis on the relationship between extreme weather and residential electricity demand. First, we built OLS and FE models to evaluate the impact of extreme weather. Second, this paper takes 2000 as the dividing line of sample time to implement heterogeneity tests. The conclusion is that the occurrence of extreme high temperature weather has a positive effect on residential electricity demand while the emergence of extreme low temperature weather has a negative effect. And, the extreme high temperature weather is more significant before 2000, while the extreme low temperature weather is more significant after 2000. In addition, the model is only applicable to the interpretation of residential electricity consumption, but has certain limitations for commercial and industrial electricity consumption which is less affected by extreme weather.

\section{References}

1. M. Zhang, C. Bai, Journal of Cleaner Production, 194, 253(2018).

2. Y. W. Su, Energy Policy, 124, 36(2019).

3. Chung W. S., Tohno S., Sang Y. S., Applied Energy, 86, 1902(2009).

4. Q. Y. Wu, Ecological Economy, 33, 2(2017).

5. Y Sun, S Wang, X Zhang, et al, Energy, 12, 120 (2021).

6. Kraft A, Kraft J, Journal of Energy \& Development, 3, 401(1978).

7. Ihara T, Kikegawa Y, Asahi K, et al, Applied Energy, 85, 12(2008).

8. Tarek N., Lester C., Energy Economics, 59, 149, (2016).

9. L. Wenz, et al, Proceedings of National Science Academy, 114, 7910(2017)

10. Y. Wang, J. Bielicki, Energy, 142, 473(2018).

11. Anna A., Giuseppe ., C. Shen, Energy, 177, 44, (2019).

12. Y. T. Li, et al, Proceedings of National Science Academy, 116, 472(2019).

13. Karimu A,Mensah JT, OPEC Energy Review, 9, 322(2015).

14. Vennemo H., Aunan K., He J. W. et al, Ecological Economics, 64, 893(2008).

15. Gary G., Environment reporter, 10, 487(2009). 